\title{
LOS AÑOS SESENTA Y EL TEMA DE LA DEPENDENCIA
}

\author{
Enzo Faletto V.
}

En 1961, Albert Hirschman escribía un ensayo con el título de Ideologías sobre el desarrollo económico en América Latina y en el entregaba una amplia visión de los que habían sido los planteamientos principales respecto a ese tema, desde el proceso de la Independencia hasta el momento en que escribía el artículo. La relectura del ensayo de Hirschman, me ha llevado a tratar de situar el tema de los orígenes de la llamada "teoría de la dependencia" como un momento de la historia de las ideas en nuestra región.

Por cierto, la "teoría de la dependencia" no aparece circunscrita a un campo específico de la realidad, ni a una disciplina en particular. Es así que se ha hablado de "dependencia económica", "dependencia política" o de "dependencia cultural" y, tanto en la elaboración de los temas como en el debate acerca de los mismos, han participado economistas, sociólogos, politólogos, historiadores y -lo que no es menos importante- personas vinculadas estrechamente al hacer político concreto. Aparece así respecto al tema de la dependencia, un rasgo muy propio de la cultura latinoamericana; sus opciones de futuro se constituyen en un punto de reflexión casi obligada para todos aquellos que en distintos campos desempeñan una función intelectual.

El artículo a que hacemos referencia es ilustrativo a este respecto. Por ejemplo, refiriéndose a los años veinte, Hirschman hace mención a la importancia que adquieren las ideas de dos grandes intelectuales y políticos latinoamericanos -ambos peruanos- Haya de la Torre y Mariátegui. Sus pensamientos están políticamente motivados, pero, son innegables sus contribuciones a la definición de las opciones económicas de los países de la región.

Así, Haya de la Torre en sus primeros escritos, al sostener polémicamente que el imperialismo no era la "última etapa del capitalismo" en América Latina, sino que la primera, postulaba que lo que correspondía era que, más que anticapitalista, se debía ser anti-imperialista. Del mismo modo, Mariátegui, rescataba el pasado indígena para que a partir de él y basándose en la organización comunitaria agraria, fuera posible construir un futuro socialista en su país y quizás, en aquellos con similar condición.

Siempre refiriéndose al tema de las ideologías económicas, Hirschman no vacila en citar a dos literatos mexicanos, Octavio Paz en El Laberinto de la Soledad y Carlos Fuentes en La Región Más Transparente, en donde, la reflexión sobre la situación económica mexicana -sus 
posibilidades de desarrollo, el carácter del mismo, las relaciones de "dependencia" con Estados Unidos- son temas constantes de sus ensayos o de la trama novelística.

Hirschman pone de relieve el que ha existido un tema siempre presente en el pensamiento latinoamericano -y subrayo que se trata del conjunto del pensamiento y no sólo de los economistas estricto-sensu-, este tema es el del "atraso", frente al cual, han surgido dos preguntas claves, la primera: ¿Dónde se encuentra la responsabilidad de nuestro atraso? ¿En nosotros o en el extranjero que nos explota?; la segunda: ¿Cómo podemos progresar? ¿Imitando a otros -y durante largo tiempo los modelos fueron preferentemente Estados Unidos o la Unión Soviética- o creando nuestro propio camino?

Es evidente que las dos preguntas señaladas constituyen el centro de la temática de la dependencia y en tal sentido los que contribuyeron a elaborarla son herederos de una larga tradición de pensamiento. Por cierto, las respuestas que ellos dieron aparecieron como polémicas respecto a otras que se daban o se habían dado y. lo que no es menos importante, eran polémicas al interior mismo de los que cubría el amplio título de "dependentistas".

No es mi intención ahora el hacer referencia a la "polémica sobre la dependencia"; son muchos los estudios y escritos sobre el tema y algunos con complicadas exégesis teóricas que escapan con mucho a mi competencia. El propósito es otro, recuperar el momento histórico tanto en términos de acontecimientos como de ideas- en que se ubica la temática de la dependencia y, de esa forma, contribuir a situarla en una perspectiva temporal que la liga con otros hechos y la dimensiona en su significado.

Dicho sea entre paréntesis, nuestro amigo, el sociólogo Adolfo Gurrieri, señalaba en uno de sus escritos la tendencia a una especie de antropofagia intelectual que a veces parecía apoderarse de los latinoamericanos, en donde se elaboraban teorías y pensamientos para ser olvidados rápidamente una vez consumidos; quizás, el historizar las ideas pueda contribuir a evitar el perseverar en esa costumbre.

Por cierto, la intención que señalo sólo la podré cumplir en esta ocasión de modo muy precario, atentan contra ella las limitaciones de un ensayo apresurado y lo selectivo de la memoria. Pero, al igual que yo, muchos de los que aquí se encuentran fueron parte de esa época; ellos remediarán los olvidos, involuntarios algunos y no tanto otros.

Y ya que hacemos recurso a la memoria, podrá perdonárseme, partir con una referencia muy personal. El ensayo Dependencia y Desarrollo en que colaboré con Fernando H. Cardoso fué escrito -como se señala en el prólogo- entre 1966 y 1967; el libro de Regis Debray, Revolución dentro de la Revolución, se publicaba en Cuba en "Casa de las Américas" en Enero de 1967; en Octubre del mismo año era muerto en Bolivia el Ché Guevara. El simple recuerdo de esas fechas sitúa el tema de la dependencia en su contexto y empieza a perfilar el momento en que se constituye.

Pero es importante, además, hacer referencia al lugar geográfico en donde -y no por azarun gran número de personas vinculadas al tema se encontraban a mediados de los años sesenta; se trata como todos ustedes recuerdan de Santiago de Chile y, ahí, también sucedían cosas. Por una parte Chile era sede, desde un cierto tiempo, de instituciones cuyo propósito era desarrollar un pensamiento latinoamericano; tal era el carácter de CEPAL y de ILPES; de ESCOLATINA y de FLACSO; como también de centros universitarios, principalmente de la Universidad de Chile; como el CESO, el Instituto de Economía o la Escuela de Sociología. La particularidad de estas instituciones o centros era que habían logrado congregar a un número considerable de 
latinoamericanos y proporcionaban un ámbito de intercambio intelectual, tanto al nivel del pensamiento como al nivel de experiencias político-sociales. No es necesario recordar acá el importante número de intelectuales brasileños que tuvieron la experiencia de Chile en esos años -el nombre de muchos de ellos aparece vinculado al tema de la dependencia- pero junto a ellos, se encontraban argentinos, uruguayos, peruanos, bolivianos, mexicanos, guatemaltecos y para qué seguir enumerando.

Se trataba entonces de un privilegiado lugar de encuentro que representaba, además, la posibilidad de vivir una experiencia política que no era muy común al conjunto de los países latinoamericanos. Chile de esos años, exhibía una estructura política-institucional con largo tiempo de funcionamiento, con un sistema de partidos y organizaciones sociales capaces de expresar y de movilizar a distintos sectores de la población y que, si no estaba exenta de conflictos, incluso graves, parecía disponer de alguna capacidad para resolverlos. La experiencia del gobierno democrata-cristiano, entre los años 1964 y 1970, fue una experiencia de transformaciones sociales -como la que tuvo lugar con la Reforma Agraria- y de redefinición de las relaciones económicas con el capital extranjero - "chilenización del cobre"- que parecían corresponder a las aspiraciones más progresistas de la política kennediana para América Latina, conocida como "Alianza para el Progreso". El posterior gobierno de la Unidad Popular, por lo menos en sus inicios, parecía también llevar a cabo algo inédito, no solo en América Latina sino también en el ámbito mundial: "La Transición Pacífica al Socialismo".

Por cierto que el ambiente político social que se vivía en Chile tiene que haber influido en algunos de los rasgos que adquirió el debate sobre la dependencia. El tema de los modos y límites que adquirían los procesos de transformación, el carácter de los mismos, el papel de las clases y grupos sociales, aparecían como posibilidades no solo estrictamente "teóricas", sino que además se mostraban como opciones de real concreción. No obstante hemos hecho referencia a que una particularidad del caso chileno, respecto al ámbito intelectual, era que Santiago de Chile se constituyó en la sede de varios organismos cuyo tema era el conocimiento de la región, en ellos se congregaban un amplio número de latinoamericanos, de modo tal que el conjunto de la experiencia era analizada.

Creo que es de interés recuperar algunos rasgos de la experiencia político-social latinoamericana y situar el tema de la dependencia en ese contexto. Gran parte del debate aparece como estrictamente vinculado a su mayor o menor rigor teórico, por ejemplo, su concordancia o no con determinado tipo de interpretaciones marxistas. Sin poner en duda la válidez de esos análisis, hemos optado esta vez por tratarlo desde la óptica de una "historia de las ideas", de modo que relevaremos, aunque solo sea de manera muy indicativa, el contexto en que tuvo lugar.

El panorama político de los años cincuenta en América Latina fue bastante agitado, en 1952 tenía lugar en Bolivia la revolución del MNR; en Brasil, en 1954 se produjo el suicidio de Vargas; Perón, en Argentina, era derrocado en 1955; en Colombia, en 1956 era depuesto Rojas Pinilla; Pérez Jiménez en Venezuela caía en 1958; en 1959, Fidel Castro entraba en La Habana. En casi todos los países de la región se despertaron expectativas de democratización, de cambios económicos y de ampliación de los procesos de incorporación y de participación política y social. No obstante, en la mayoría de los casos, las expectativas generadas no lograban cumplirse; en parte porque el propio proceso de cambio generaba conflictos que los grupos de poder no estaban dispuestos a asumir -dado que afectaban sus posiciones de privilegio-, o porque los gobiernos que habían asumido la nueva conducción política, tensionados por las pugnas sociales, se mostraban incapaces de resolverlas, defraudando las esperanzas puestas en ellos. 
Unas breves menciones nos harán recordar la atmóstera que vivíamos en los años que corresponden a las décadas de los cincuenta y de los sesenta. En Argentina. Frondizzi fue elegido en 1958 con votos peronistas, de él se esperaba una política de empuje "desarrollista" y en cierto sentido, nacionalista, tal como se desprendía de su famoso libro Política y' Petróleo. Fue depuesto por un golpe militar en 1962. No corrió mejor suerte llia, que, elegido en 1963, fue depuesto por el golpe de Ongania en 1966; a Onganía le sucedió el general Levingston (1969-1971) y a éste, el general Lanusse (1971-1973). Como es sabido, el problema constante de Argentina era el problema del peronismo, al que políticamente se trataba de excluir, pero la exclusión política era también, en gran medida, exclusión social. La no resolución del problema peronista, significaba la imposibilidad de funcionamiento de un sistema político-institucional $y$, aún bajo regímenes militares, amenaza constante de inestabilidad. La protesta social no estaba ausente -baste recordar el "Cordobazo" en 1969- como tampoco lo estaba la violencia; en 1970 iniciaron su acción los "montoneros".

En Brasil -solo para no omitir, dado que estamos acá- recordemos la elección de Janio Quadros en 1960 y su dimisión en 1961, su reemplazo por Goulart hasta el golpe de estado por Castelo Branco en 1964. No pecaremos de entrometidos si graficamos el cambio y las tensiones del período post-vargas, mencionando a Kubitschek y la creación de Brasilia; la creación del SUDENE en 1959 y la formación de las Ligas Campesinas (1955-1959); la elección de Miguel Arraes en Recife en 1962.

Otros dos países son claros indicativos de las tensiones y conflictos de la época: en Venezuela, el gobierno electo de Rómulo Betancourt en 1958 -después del derrocamiento de Pérez Jiménez con dificulad lograba enfrentar los conflictos políticos; su propio partido, Acción Democrática. sufrió un fuerte quiebre en 1960, la gran mayoría de la juventud se separó del partido y lo mismo hicieron una fracción importante de los diputados, dando origen al MIR venezolano. A partir de 1962 se instalaron las guerrillas en Venezuela. El descontento urbano siempre estuvo presente, especialmente el estudiantil; en 1966. el ejército ocupó la Universidad.

En Perú, el problema se había planteado tradicionalmente con el veto de los militares al APRA, aunque el partido fundado por Haya de la Torre había buscado formas de convivencia con el régimen, tal como lo demostró durante el gobierno de Prado ya en 1956; no obstante, en 1962, un golpe militar impidió la elección de Haya de la Torre. Pero no solo problemas con el APRA existian en Perú; el problema campesino también era de magnitud, entre los años 62 y 63 se produjo la movilización de campesinos del valle de La Convención (Hugo Blanco). El gobierno electo de Belaunde Terry (1963) emprendió el proceso de la Reforma Agraria; pero, en 1965 surgieron los focos guerrilleros conducidos por Lobatón. De la Puente y Béjar. Los militares dieron un golpe de Estado en 1968 pero éste no tuvo el tinte tradicional; en 1969 Velasco Alvarado profundizaba la Reforma Agraria y asumía políticas de corte nacionalista.

No es necesario hacer un recorrido por todos los países para recordar lo conflictivo de la época. Baste mencionar el golpe de estado de Barrientos en Bolivia en 1964; el gobierno de Pacheco Areco en Uruguay en 1968 y la masacre de Tlatelolco en México en el mismo año. Y, ¿qué pasaba en Cuba, que para tantos de los intelectuales latinoamericanos se había constituído en el gran ejemplo? También ahí, un conjunto de fechas pueden servir de recordatorio. En 1960 , se produjo la ruptura económica con Estados Unidos y el acuerdo económico con la URSS; en 1961, Fidel Castro proclamaba el carácter socialista de la Revolución. El mismo año, en Abril, el desembarco de Playa Girón, auspiciado por el gobierno de Estados Unidos; en 1962, ruptura de la OEA con Cuba y la "crisis de los misiles"; en 1965, el Ché Guevara dejaba el Ministerio de 
Industria; se creaba el Partido Comunista Cubano. En 1966 tenía lugar la Conferencia Tricontinental de La Habana y se daba origen a la OLAS.

Vemos entonces que el tema de la dependencia surge en medio de una experiencia política extraordinariamente compleja, en donde abundan conflictos y frustraciones, pero también momentos de expectativas y esperanzas. Formalmente, los distintos ensayos y estudios sobre la dependencia se inscribían en la llamada "Teoría del Desarrollo" y eran polémicos con planteamientos que hasta ese entonces habían estado muy en boga. Lo que los dependentistas plantearon, era que las opciones económicas distaban mucho de ser neutrales y que tenían claro significado político; que podían beneficiar a algunos y afectar negativamente a otros. En suma, el problema del desarrollo era un problema de poder, pero si a veces no era tan difícil definir el rasgo del poder existente, más complicado era definir el carácter del poder posible y aquí, a menudo, la pugna se instaló al interior de los propios "dependentistas".

Como se ha dicho, la polémica adquiere en algunos casos una marcada sofistificación teórica, pero más allá del debate intrínseco, conviene insistir en el contexto en que tal discusión se llevaba a cabo. En el plano ideológico general en los años sesenta se producían transformaciones significativas; ilustrativo es lo que ocurrió en la Iglesia Católica. Las nuevas orientaciones "progresistas" de la iglesia generaron grupos cuyo lenguaje y preocupaciones no diferían ya tanto de la izquierda tradicional, surgieron incluso personajes como Camilo Torres y en algunos países grupos de estudiantes de izquierda católica se transformaron en movimientos políticos juveniles de proyección nacional, como fué el caso de Acción Popular en Brasil en los años pre sesenta y cuatro. El hecho es que muchas de las opciones ideológicas tendían a hacerse extremas y la influencia de la Revolución Cubana, particularmente en la juventud, era innegable. El tema de la "vía violenta" adquiría presencia y no pocos concebían la lucha armada como perspectiva inevitable para América Latina. Quizás uno de los efectos importantes fue la ruptura al interior de lo que antes se había considerado el "progresismo", al insistirse en que los movimientos revolucionarios debían evitar, por todos los medios, caer en la "trampa de la legalidad". Entre los jóvenes -y en no pocos intelectuales- campeaba un nuevo valor, el valor de la rebeldía, y se negaba el de la "moderación"; por ese camino era casi inevitable la desautorización a "los viejos políticos". La manera de enfrentar las necesarias reformas estructurales debía superar las tímidas prácticas que se habían intentado; el ejemplo era la Reforma Agraria, no se trataba -se decía- "de dar a los campesinos la tierra que sobra, sino la que está en poder de los latifundistas". Para recordar parte del clima de la época, baste hacer mención al atractivo que ejerció la idea de formar al "hombre nuevo" o la difusión de teorías educativas liberadoras como las de Paulo Freire.

Tan ilustrativas como las ideologías políticas lo son para el contexto en que se sitúa la temática de la dependencia, lo son también algunas manifestaciones culturales de los años sesenta, por ejemplo la literatura. Son los años en que se difunden Sábato, Cortazar, Onetti, Benedetti, Vargas Llosa, García Márquez y tantos otros que harían una larga lista. Es una literatura que se separa del "realismo social" de los escritores de los años treinta y cuarenta, sus personajes y su trama es menos esquemática y, sin que desaparezca la "preocupación social", la preocupación por el individuo está mucho más presente. Para varios críticos de la literatura latinoamericana la nueva novela es expresiva de una nueva forma de conciencia, donde el tema común a casi todos es el de desentrañar qué es la realidad latinoamericana, pero se trata de una realidad que no es ajena a la conciencia de si mismo.

Es alrededor de este tema que en el campo de la creación literaria tienen lugar ciertas 
polémicas: ¿Es posible la escisión del ser político y el ser literario? Para aigunos, la "revolución" y la adhesión a la misma es la piedra de toque, la única posibilidad real de afirmación cultural. Quien no la asume plenamente corre el riesgo de transformarse en tránsfuga. desertor, apátrida o "viejos incondicionales regresando a la comodidad de su liberalismo". El escritor -se sostiene- es escritor e intelectual, si sus ideas no son "correctas" no describirá bien la realidad. Hay que ser a la vez escritor y revolucionario.

No son ajenas a este clima otras manifestaciones culturales y quizás en algún momento sería el caso de hacer una consideración detenida de lo que significó el Cinema-Novo brasileño. Como algunos de sus críticos han señalado, no estuvo exento de una cierta simplificación en el plano ideológico. A menudo solo aparecían dos grandes tipos: los pobres y los ricos, estos últimos depravados y ociosos. Lo que primaba era un juicio moral de condena al "burgués", los personajes de clase media -cuando los hay- son personajes oscilantes entre dos polos: la revolución encarnada por los pobres y el status-quo de la burguesía decadente.

Este clima de confrontación, con sus simplificaciones ideológicas, es muy propio de los finales de la década del sesenta y principios de los setenta. El problema del cambio histórico y la transformación social se planteaba de tal manera que las opciones se presentaban como antagónicas entre sí. La alternativa de una amplia "alianza desarrollista", que había constituido la aspiración de muchos gobiernos y actores políticos, no encontraba posibilidades de viabilidad.

De hecho, el "desarrollismo" de los años cincuenta y sesenta había intentado conjugar dos dimensiones: el impulso a procesos de modernización con propuestas políticas y económicas de un cierto nacionalismo. No obstante, conjugar las dos dimensiones no era tarea fácil, una serie de hechos conspiraban contra esa posibilidad. El propio proceso de cambios actuaba a veces en sentido contrario al esperado. Por ejemplo, el desarrollo industrial, que se había concebido como la oportunidad de creación de una industria nacional, al hacerse más complejo implicaba mayor dependencia tecnológica, necesidad de insumos externos y muy a menudo financiamiento extranjero. Además. se estaba produciendo un movimiento internacional de capitales en donde hubo una cierta transferencia desde el centro a la periferia. El hecho significativo era que las propias corporaciones industriales internacionales actuaron como inversores. La asociación entre empresarios extranjeros y nacionales pasó a acentuarse.

Si en el momento de inicio de las llamadas "opciones desarrollistas" la oposición entre lo "moderno" y lo "tradicional" parecían ser el parte-aguas de las opciones sociales, a poco andar, los conflictos al interior de la modernidad, o más bien al interior de la supuesta alianza modernizadora, adquirieron gran importancia. En muchos casos fue el tema de la Reforma Agraria - un sector casi por definición, en esos momentos, atrasado y tradicional- el que provocó la quiebra de la citada "alianza desarrollista". La defensa de la "propiedad amenazada" volvía a hacer solidarios entre sí al conjunto de los "propietarios".

Lo importante es que la propuesta de modernización y nacionalismo implicaba dos dimensiones de concreción: desarrollo económico y participación. Pero los distintos grupos sociales comprometidos en el proceso ponían énfasis distintos en cada uno de ellos. Por ejemplo, en relación a la "Reforma Agraria" supuestamente -en teoría- debían articularse ambas dimensiones, en la medida en que esta significaba nuevas opciones de dinamismo económico -ampliación del mercado interno, mayor producción de bienes salarios, etc.- y a la vez incorporación y participación nacional de los campesinos. De hecho, los grupos altos privilegiaban el primer significado, en cambio los campesinos el segundo. 
No solo se trataba de que algunos sectores sociales privilegiaran más una dimensión participación o desarrollo- que la otra; los contenidos concretos que se otorgaban a las nociones de modernización o nacionalismo diferían entre sí. Respecto a la idea de modernización, los sectores populares entendían por tal la constitución de formas e instituciones que levantaran las barreras de segregación social y permitieran el reconocimiento de la condición ciudadana. La modernización significaba para ellos la posibilidad de participación política y de constituir modos de organización (sindicatos u otros) que dieran la posibilidad de expresión e inserción en la sociedad.

Para los sectores medios, la modernización también significaba apertura del sistema existente y acceso al mismo, pero muchas veces el objetivo se concretaba en términos de obtener mayores posibilidades de movilidad individual. La idea de modernización en esos sectores también se ligaba estrechamente a la ampliación y acceso al consumo. En los sectores altos, en cambio, primaban como ideas de modernización las nociones de racionalización y mayor productividad.

Algo similar sucedía con el concepto de nacionalismo. Los sectores altos, cuando lo asumían, enfatizaban la constitución de una legitimidad política que hiciera posible representarse como nación en el ámbito de las relaciones externas. Para los sectores medios la idea de nación se identificaba con la de ciudadanía, lo que se ligaba a su demanda constante por ampliar su cuota de participación en las decisiones del poder político. Para los sectores populares el nacionalismo era fundamentalmente integración, lo que implicaba participación, tanto política como económica y social.

Como muchos han señalado, la viabilización del proyecto desarrollista tenía un agente clave, el Estado. En la definición del mismo se repiten las contradicciones que estaban presentes en los distintos contenidos adjudicados a las ideas de modernización y nacionalismo. Es así que para los sectores populares la definición del Estado giraba en torno al tema de la participación y la integración social; para los sectores medios el desarrollo del Estado significaba movilidad y acceso a la administración del poder; para los sectores altos, el Estado era preferentemente un instrumento de política económica.

De hecho, en el momento histórico en que la problemática de la dependencia surge como tema de análisis, la pugna social ya no sólo estaba signada por la oposición "tradicional-moderno"; lo que se discutía eran las "orientaciones de desarrollo" y, en torno a estas, los distintos grupos sociales trataron de constituir sus propias opciones. La mayor parte de los escritos sobre la dependencia no escapaban a esta intención.

Para finalizar, tratemos de hacer explícitas nuestras preocupaciones: ¿Por qué situar en su contex to histórico el tema de la dependencia? Por cierto, siempre existe una necesidad de establecer una relación entre el pasado y el presente; necesidad que es más urgente hoy día en que existe una fuerte presión para asumir el presente como lo único válido e inconmovible. ¿Es la temática de la dependencia una herencia que hay que rechazar o asumir? ¿Qué problemas, de los planteados por los estudios sobre dependencia, siguen hoy vigentes? ¿Cómo reformularlos?

Uno de los temas significativos -de los cuales el debate sobre la dependencia fue parte- es el problema nacional y la conflictiva relación entre sistema internacional y sistemas nacionales, en donde el modo en que ambos se articulan no es ajeno a las formas en que se constituye el poder interno. 
El tema de la gestión del desarrollo no es un problema neutral y de pura resolución tecnocrática. Se trata de opciones de sociedad y de la posibilidad de intervenir en los procesos de transformación de la vida social. Y a esta gestión no le son ajenos los valores culturales e incluso éticos.

¿Vale la pena estudiar lo dicho por los dependentistas y las interpretaciones que dieron? En gran medida, el análisis del tema de la dependencia es, también, el análisis del papel de los intelectuales en un momento de la historia latinoamericana y -para bien o para mal- los intelectuales son productores de ideologías. ¿Cuál es el papel de las ideologías en los procesos económicos? El tema de la Nación operó en el desarrollo latinoamericano como ideología. ¿Hemos terminado con el tema de la Nación? ¿La participación de las masas es pura ideología "populista", o un problema real? Y por último, ¿Cambiar las reglas de la sociedad capitalista actual es una idea en desuso? 